\title{
Treatment of Class II malocclusion with bialveolar protrusion by means of unusual extractions and anchorage mini-implant
}

Jong-Moon Chae'

Introduction: Patients with dental Class II bialveolar protrusion are generally treated by extracting the four first premolars or two first and two second premolars, and retracting the anterior teeth. This case report describes the treatment of an adult patient with bialveolar protrusion, a Class II canine and molar relationship, and lip protrusion. Methods: In this patient, the maxillary right second molar (1.7) had to be extracted due to extensive caries. To create sufficient space to retract the anterior teeth, the maxillary right posterior teeth were distalized with a maxillary posterior mini-implant (1.2 1.3 mm in diameter, 10 mm long), which was placed into the maxillary tuberosity area and allowed an en masse retraction of the maxillary anterior teeth. Results: Overall, mini-implant can provide anchorage to produce a good facial profile even without additional premolar extraction in cases of dental Class II bialveolar protrusion with the hopeless second molar. Conclusion: The total treatment period was 42 months and the results were acceptable for 34 months after debonding.

Keywords: Mini-implant. Tooth extraction. Tooth movement.

Introdução: os pacientes com Classe II e biprotrusão alveolar são, geralmente, tratados com extração de quatro primeiros pré-molares ou dois primeiros e dois segundos pré-molares, e retração dos dentes anteriores. Este relato de caso descreve o tratamento de um paciente adulto com biprotrusão alveolar, relação de caninos e de molares em Classe II e protrusão labial. Métodos: nesse paciente, o segundo molar superior direito precisou ser extraído devido a cáries extensas. Para criar espaço suficiente para retração dos dentes anteriores, os dentes posterossuperiores direitos foram distalizados com um mini-implante posterossuperior (1,2 1,3mm de diâmetro, 10mm de comprimento), que foi colocado na área da tuberosidade maxilar e permitiu uma retração em massa dos dentes anteriores. Resultados: em geral, mini-implantes podem fornecer ancoragem para produzir um bom perfil facial, mesmo sem extração adicional de molares em casos de Classe II com biprotrusão alveolar. Conclusão: o período total de tratamento foi de 42 meses e os resultados 34 meses após a remoção do aparelho foram aceitáveis. Palavras-chave: Parafusos ósseos. Extração dentária. Movimentação dentária.

${ }^{1}$ Professor of the Orthodontics Department of the Wonkwang University, Iksan/ Wonkwang Dental Research Institute, Korea.

\author{
How to cite this article: Chae JM. Treatment of Class II malocclusion with bialveo- \\ lar protrusion by means of unusual extractions and anchorage mini-implant. Dental \\ Press J Orthod. 2012 Sept-Oct;17(5):165-77. \\ Submitted: October 27, 2011 - Revised and accepted: February 15, 2012 \\ » The author reports no commercial, proprietary or financial interest in the products \\ or companies described in this article. \\ » Patients displayed in this article previously approved the use of their facial and in- \\ traoral photographs. \\ Contact address: Jong-Moon Chae \\ E-mail: jongmoon@wonkwang.ac.kr.
}




\section{INTRODUCTION}

Bialveolar protrusion is a condition characterized by protrusive and proclined upper and lower incisors and an increased procumbency of the lips. The goals of orthodontic treatment of bialveolar protrusion include the retraction and retroclination of maxillary and mandibular incisors with a resultant decrease in soft tissue procumbency and convexity. ${ }^{1}$

A common treatment approach for patients with Class II bialveolar protrusion is to extract 2 maxillary premolars or 2 maxillary and 2 mandibular premolars, and retract the anterior teeth using maximum anchorage mechanics. ${ }^{2,3,4}$ However, the treatment plan becomes more complex and controversial when a patient has hopeless maxillary second molars that should be extracted and wants to preserve maxillary premolars.

To solve this situation, the maxillary posterior teeth should be distalized. Distal movement of the maxillary molars is often used in the correction of Class II malocclusions, and various appliances have been proposed. However, the distal movement of molars has been considered as one of the most difficult biomechanical problems to achieve treatment objectives in clinical orthodontics.

Conventional distalization mechanics either rely on considerable patient compliance or generate unwanted reciprocal movement of anchor teeth in the anterior segment. Moreover, once molar distalization has been achieved, distalization of the anterior teeth without molar anchorage loss is challenging. The side effects such as forward movement of anterior teeth during distalization of molars and forward movement of the distalized molars during anterior tooth retraction may develop resulting in a prolonged treatment time. ${ }^{5}$

The choice of the appropriate force system to distalize the maxillary molars efficiently and retract the anterior teeth in patients with Class II malocclusion is based mainly on the anchorage conditions required to achieve the desired treatment goals.

Absolute skeletal anchorage, available 24 hours a day, offers an alternative method for molar distalization. The use of osseointegrated implants ${ }^{6}$, miniplates, ${ }^{7}$ miniscrews ${ }^{8,9}$ and microimplants ${ }^{10,11}$ as anchorage has made distalization of the posterior teeth without anchorage loss a more realistic respect.
There are few case reports involving the distalization of the maxillary posterior teeth with mini-implants (MIs) in patients with Class II bialveolar protrusion. This patient report demonstrates the use of MIs in a case of dental Class II bialveolar protrusion with the hopeless maxillary right second molar (1.7).

\section{DIAGNOSIS}

A 40 year-old woman presented with the chief complaint of lip procumbency. Facially, she exhibited a convex profile with marked protrusion of the lips, mentalis muscle strain and lip incompetence, but good vertical balance of facial proportion (middle and lower thirds) and proper maxillary incisor show on posed smile. Intrabuccally, she had a Class II canine and molar relationship except Class I molar relationship on the left side, normal overbite $(2.5 \mathrm{~mm})$, larger overjet $(10 \mathrm{~mm})$, and no significant Bolton tooth-size discrepancy. Her oral hygiene was moderate with gingival recession on several teeth, especially on the upper right canine and first premolar. There was an arch length deficiency of approximately $2 \mathrm{~mm}$ in the maxillary arch and $4 \mathrm{~mm}$ crowding in the lower arch. Dental asymmetry was present with a slight deviation of the maxillary dental midline to the left and of the mandibular dental midline to the right of the facial midline. It was just due to dental crowding and skeletal and facial asymmetry were not shown (Fig 1).

The panoramic radiograph revealed the presence of severe decay on the maxillary right second molar as well as generalized bone resorption (Fig 1). The lateral cephalogram (Fig 1) and its tracing showed dental Class II bialveolar protrusion, but Class I skeletal pattern. The skeletal pattern was normodivergent as evidenced by the FMA (Frankfort mandibular plane angle) of $29.5^{\circ}$ and the FHI (facial height index) of $60 \%$. The occlusal plane angle of $11.5^{\circ}$ (Left) and $12.6^{\circ}$ (Right) reflected the normal vertical dental pattern. The IMPA (incisor mandibular plane angle) of $98.1^{\circ}$ reflected the proclination of lower incisors. The Zangle of $65.6^{\circ}$ quantified the slight facial imbalance (Table 1). There were no significant signs or symptoms of temporomandibular disorders.

\section{TREATMENT OBJECTIVES}

The treatment objectives were to (1) align and level the teeth in both arches and establish a functional 

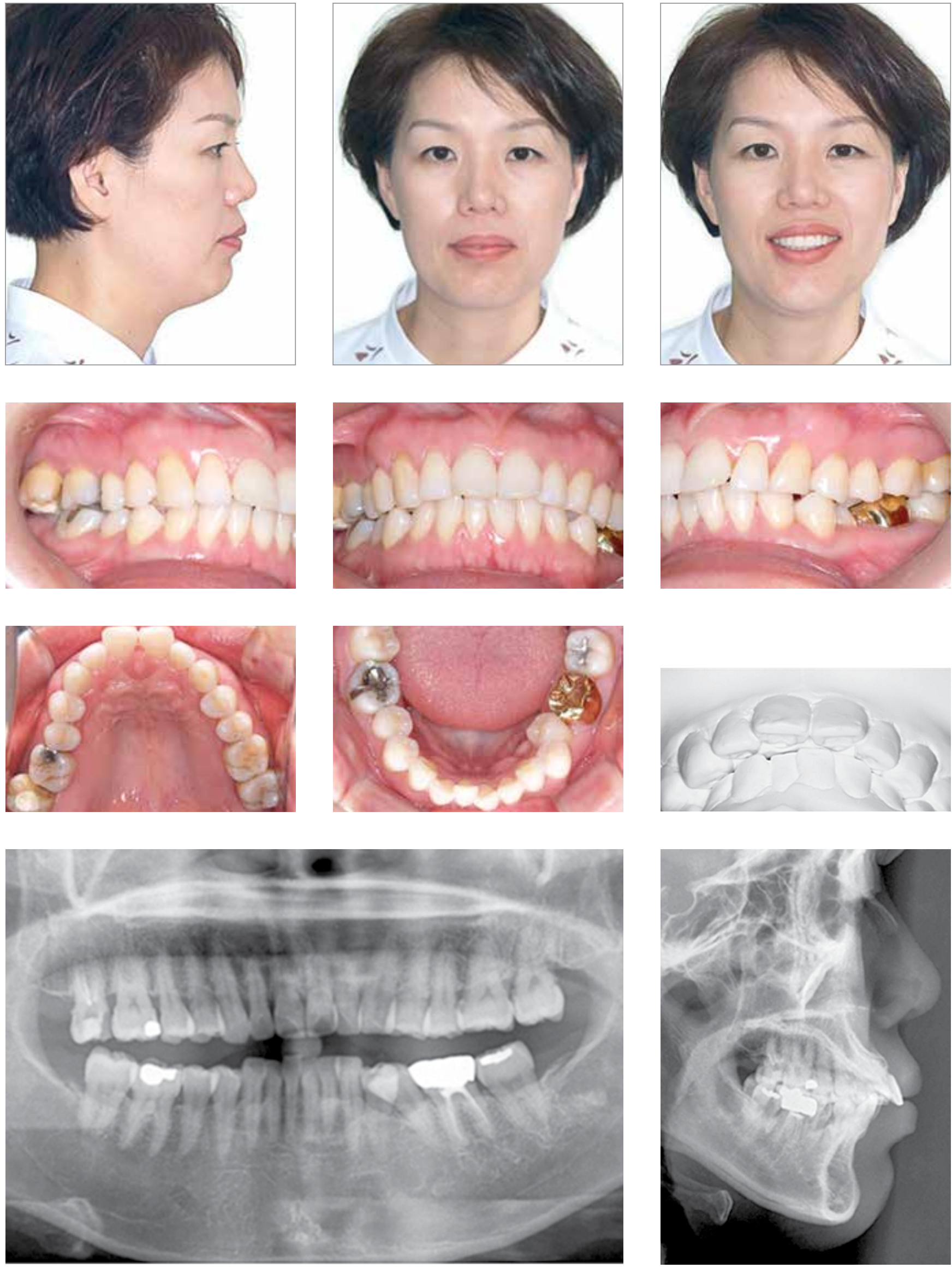

Figure 1 - Pretreatment photographs and radiographs. 
Table 1 - Cephalometric measurements.

\begin{tabular}{|c|c|c|c|c|}
\hline & Norm & Pretreatment & Posttreatment & Postretention \\
\hline FMIA (degrees) & 67 & 52.4 & 54.3 & 54.4 \\
\hline FMA (degrees) & 25 & 29.5 & 28.8 & 28.5 \\
\hline IMPA (degrees) & 88 & 98.1 & 96.9 & 97.1 \\
\hline SNA (degrees) & 82 & 74.6 & 74.5 & 74.5 \\
\hline SNB (degrees) & 80 & 73.2 & 73.5 & 73.8 \\
\hline ANB (degrees) & 2 & 1.4 & 1.0 & 0.7 \\
\hline $\begin{array}{c}\text { AO-BO (mm): } \\
\text { Right / Left }\end{array}$ & 2 & $-3.4 /-4.4$ & $-5.5 /-6.9$ & $-5.0 /-5.5$ \\
\hline $\begin{array}{c}\text { OP angle (degrees): } \\
\text { Right / Left }\end{array}$ & 10 & $11.5 / 12.6$ & $14.0 / 15.8$ & $13.1 / 14.5$ \\
\hline FH a U1 (degrees) & 112 & 126.2 & 103.1 & 103.3 \\
\hline Z angle (degrees) & 75 & 65.6 & 74.5 & 76.5 \\
\hline $\begin{array}{c}\mathrm{FHI}(\%) \\
(\mathrm{PFH} / \mathrm{AFH})\end{array}$ & $69.0(45.0 / 65.0)$ & $60.0(45.9 / 75.9)$ & $61.0(45.7 / 74.7)$ & $61.0(45.7 / 75.0)$ \\
\hline
\end{tabular}

FMIA indicates angle between Frankfort plane and mandibular incisor axis; FMA, angle between Frankfort plane and mandibular plane; IMPA, angle between lower incisor axis and mandibular plane; SNA, angle between SN and NA; SNB, angle between SN and NB; ANB, difference between the SNA and SNB angles; $\mathrm{AOBO}$, distance between perpendiculars drawn from point $\mathrm{A}$ and point $\mathrm{B}$ onto the occlusal plane; OP angle, occlusal plane angle; FH, Frankfort horizontal plane; UI, maxillary incisor axis; FH to UI, angle between Frankfort plane and maxillary incisor axis; $\mathrm{Z}$ angle, angle between FH and profile line tangent to the chin and the vermilion border of both lips; FHI, ratio of PFH to AFH; $\mathrm{PFH}$, linear measurement from articulare, along a line tangent to the posterior border of the mandible, to the intersection with the mandibular plane; and AFH, linear measurement from palatal plane to mention, measured perpendicular to palatal plane.

occlusion, (2) normalize the overjet, (3) improve dental symmetry (4) obtain a balanced facial profile.

\section{TREATMENT ALTERNATIVES}

The first alternative was retraction of the maxillary and mandibular anterior teeth using maximum anchorage following four first premolar extractions, and differential tooth movement to improve dental symmetry. To reduce the patient's lip protrusion, this option would be unavoidable. But, this would require additional prosthetic treatment. The loss of pitiful tooth and adjunctive expenditure would be a burden to the patient.

The second alternative was retraction of the maxillary and mandibular anterior teeth with simultaneous distal movement of the maxillary right posterior teeth using absolute anchorage after extraction of maxillary left first premolar (2.4) and mandibular left second premolar, and group distal tooth movement of the mandibular right posterior teeth instead of extraction of mandibular right second premolar (4.5), and differential tooth movement to improve dental symmetry.

The third alternative was the same as the second alternative exception for the extraction of mandibular right second premolar (4.5) instead of group distal tooth movement of the mandibular right posterior teeth.

In the second and third alternatives, the additional prosthesis would be avoided due to the survival of the maxillary right first premolar (1.4). These options would preserve the maxillary right first premolar (14) and result in a good result without patient compliance. In the beginning, second alternative was chosen but it was insufficient to obtain a good facial profile. Therefore, in the middle of treatment, third alternative was chosen.

\section{TREATMENT PROGRESS}

The treatment began using a new protocol of Tweed-Merrifield directional force technology with MIA $^{12}$, after extracting the maxillary right second molar (1.7) and maxillary left first premolar (2.4).

After the extractions, $0.022 \times 0.028$-in standard edgewise appliance was placed in the maxillary arch. Leveling began with a 0.016-in nickel-titanium archwire and 0.018-in, $0.017 \times 0.022$-in stainless steel arch wires. The maxillary right posterior MI $(1.3 \sim 1.2 \mathrm{~mm}$ in diameter, 10 mm in length; Absoanchor SH1312-10, 
Dentos, Taegu, South Korea) was implanted into the tuberosity area distobuccal to the maxillary right second molar (1.7). The maxillary left posterior MI (1.3 $1.2 \mathrm{~mm}$ in diameter, $8 \mathrm{~mm}$ in length; Absoanchor SH1312-08, Dentos) was implanted into the buccal alveolar bone between the maxillary left second premolar (25) and first molar (2.6). The mandibular right posterior MI (1.3 $1.2 \mathrm{~mm}$ in diameter, $7 \mathrm{~mm}$ in length; Absoanchor SH1312-07, Dentos) was implanted into the buccal alveolar bone between the mandibular right first and second molars (4.6 and 4.7). An elastic chain force was loaded immediately after placing the MIs, from the maxillary posterior MIs to the T spring inserted into the vertical slot of the canine brackets to retract the maxillary canines to level the six anterior teeth and retract the maxillary right posterior teeth. Another elastic chain force was loaded immediately after placing the MI, from the mandibular right posterior MI to the buttons on the occlusal and buccal surface of the mandibular right second molar for buccal uprighting without extrusion (Fig 2A).

Five months into the treatment, after extracting the mandibular left second premolar (3.5), $0.022 \times 0.028$-in standard edgewise appliance was placed in the mandibular arch, and leveling began with a 0.014-in nickel-titanium archwire and 0.018-in, $0.018 \times 0.025$-in stainless steel archwires. The mandibular left posterior MI (1.3 $1.2 \mathrm{~mm}$ in diameter, 7 $\mathrm{mm}$ in length; Absoanchor SH1312-07, Dentos) was implanted into the buccal alveolar bone between the mandibular left first and second molars (3.6 and 3.7). An elastic chain force was loaded immediately after placing the MI, from the mandibular left posterior MI to the mandibular left canine bracket in order to retract the mandibular left canine and first premolar to level the six anterior teeth. Another elastic chain force was loaded from the mandibular right posterior MI to the mandibular right canine bracket to distalize the mandibular right posterior teeth followed by creating space for retraction of the mandibular anterior teeth (Fig 2B).

Nine months into the treatment, $0.020 \times 0.025$-in stainless steel archwire with closing loops was placed in the upper arch to retract the four anterior teeth (Fig 2C). At this time, the patient wanted to correct lip protrusion more, but the posterior limit of mandibular arch did not allow for more distalization of the posterior teeth to satisfy the patient's esthetic desire. Therefore, a decision was made to extract the mandibular right second premolar (4.5).
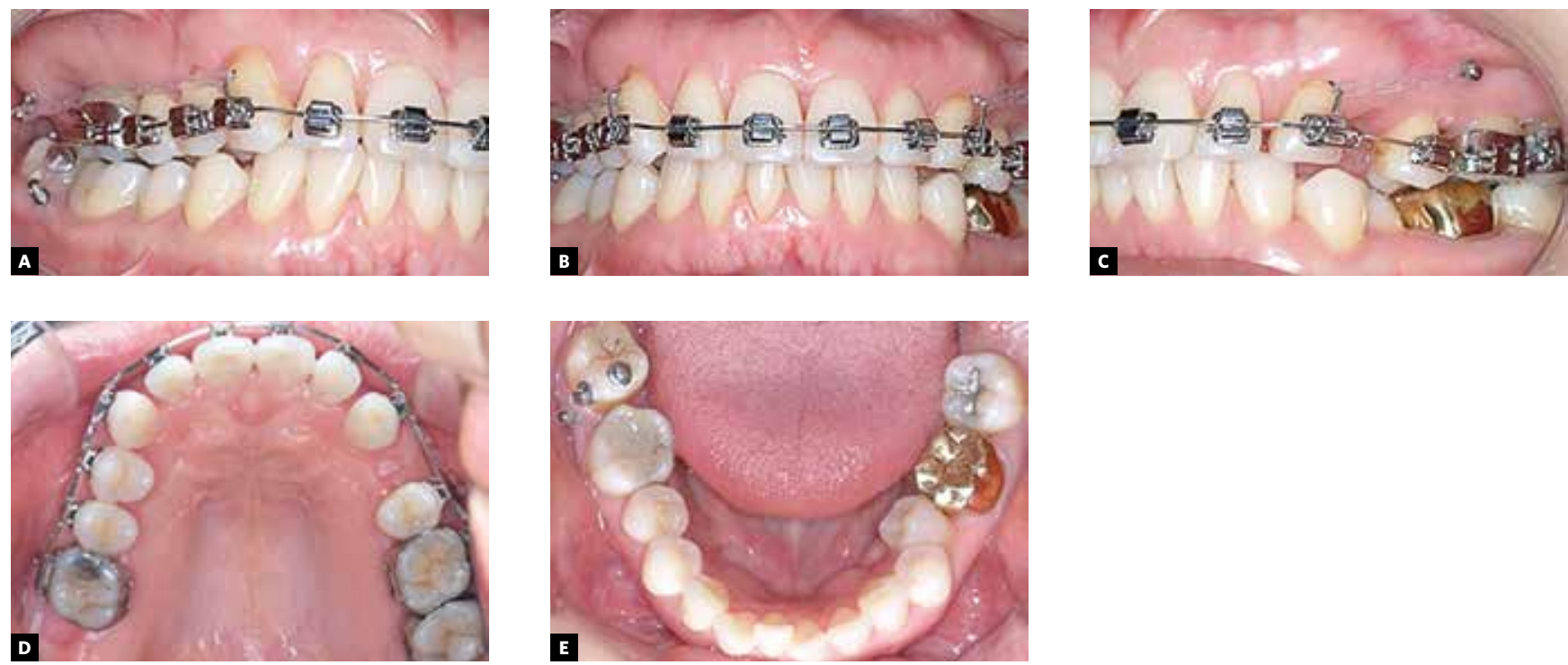

Figure 2 - Treatment progress. A) Maxillary right posterior mini-implant (MI) for distalization of maxillary posterior teeth, maxillary left posterior MI for canine retraction and mandibular right posterior $\mathrm{MI}$, and buttons for buccal uprighting and intrusion of mandibular right second molar; B) After extracting the mandibular left second premolar (3.5), distalization of mandibular right posterior teeth and retraction of mandibular left canine and premolar with mandibular posterior mini-implants; C) En masse retraction of maxillary four anterior teeth with closing loop archwire supported by maxillary posterior miniimplants; D) Maxillary anterior mini-implants for intrusion and torque control, running loop for uprighting and mesial movement of mandibular molars, and retraction of mandibular anterior teeth; E) Mandibular right middle mini-implant for protraction of mandibular right molars and Clip on maxillary anterior mini-implants to prevent soft tissue irritation. 

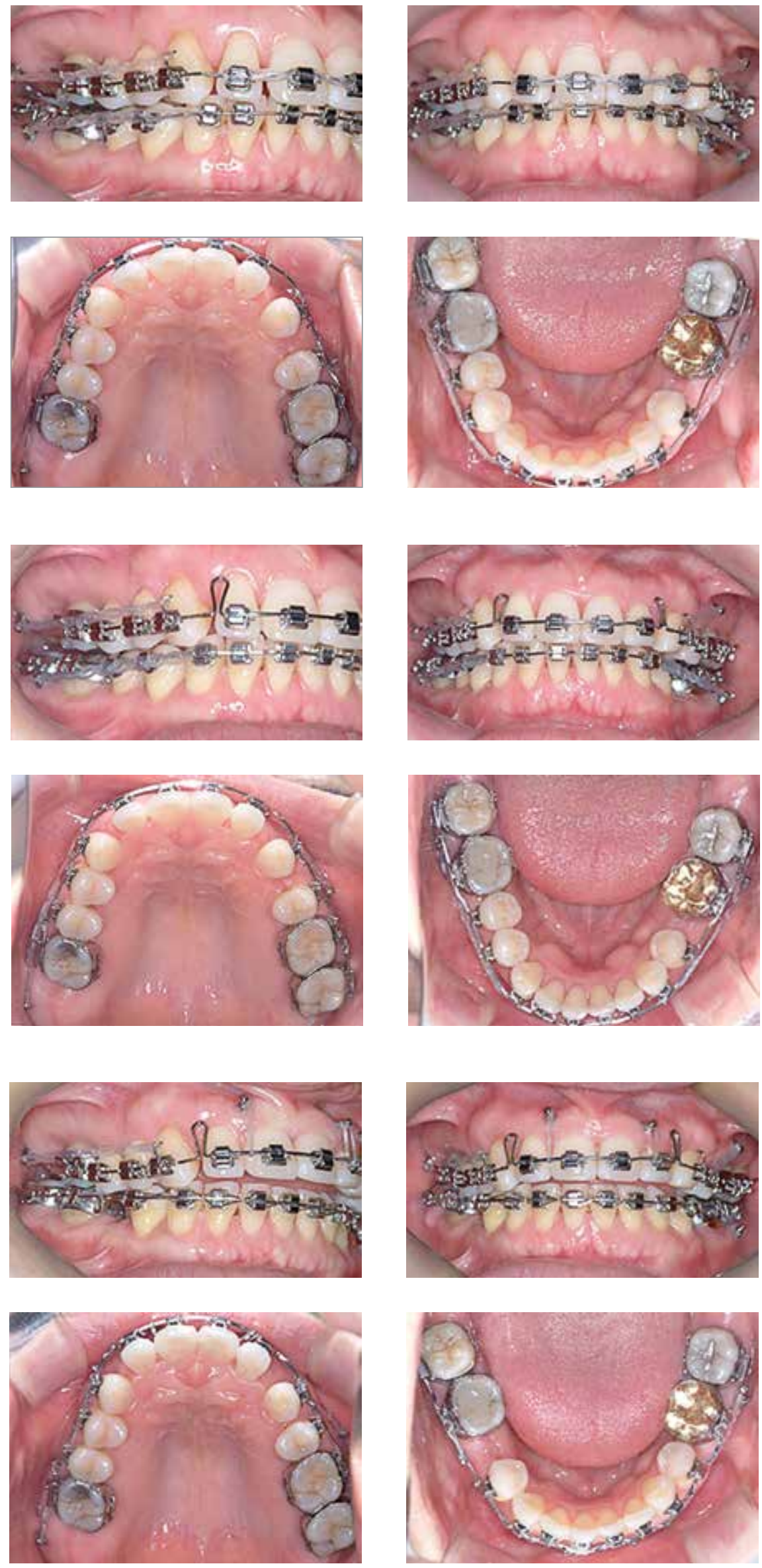

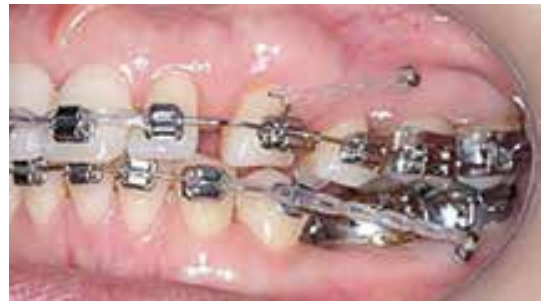

Figure 3 - Progress of treatment. After extraction of the second left premolar (3.5), distalization of right posterosuperior teeth and retraction of lower left canine and posterosuperior premolars with mini-implants.

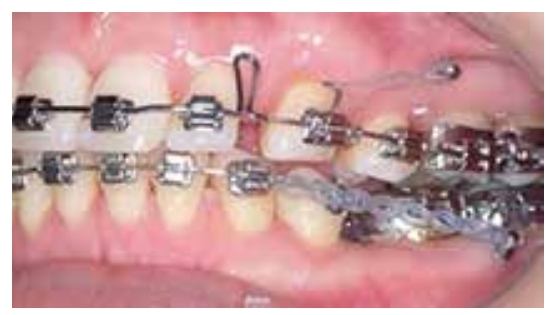

Figure 4 - Progress of treatment. En masse retraction of the four anterior teeth with closing loop arch wire supported by posterosuperior mini-implants.

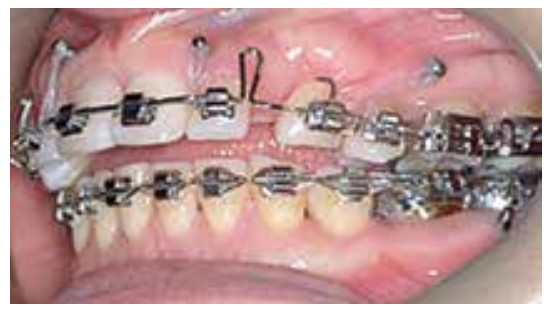

Figure 5 - Progress of treatment. Anterior superior mini-implants for intrusion and torque control, running loop for uprighting and mesial movement of mandibular molars and retraction of mandibular anterior teeth. 
After the extraction, $0.018 \times 0.025$-in stainless steel arch wire with running loops was placed in the lower arch to retract anterior teeth and protract the posterior teeth with minimal anchorage concept. Twelve months into the treatment, the maxillary anterior MIs (1.3 $1.2 \mathrm{~mm}$ in diameter, $7 \mathrm{~mm}$ in length; Absoanchor CH1312-07, Dentos) were implanted into the labial alveolar bone between the maxillary central incisors and the lateral incisors for torque control, bodily movement and intrusion of the maxillary anterior teeth (Fig 2D).

During en masse movement in the maxillary arch, a mandibular middle MI $(1.3 \sim 1.2 \mathrm{~mm}$ in diameter, $7 \mathrm{~mm}$ in length; Absoanchor SH1312-07, Dentos) was implanted into the labial alveolar bone between the mandibular right canine and first premolar (4.3 and 4.4) to protract the mandibular right posterior teeth to achieve Class I dental relationship. Light curing temporary material (Clip, Voco, Germany) was applied to the upper anterior MIs to reduce the level of soft tissue irritation (Fig 2E).

The treatment was completed with ideal archwires and cusp-seating elastics. Fixed lingual retainers were bonded to the lingual sides of the six anterior teeth and circumferential clear retainers were placed on both arches, immediately before and after removing the appliances for retention, respectively. The total treatment time was 42 months.

\section{TREATMENT RESULTS}

The posttreatment facial and intraoral photographs, and dental casts revealed a nicely balanced and harmonious face by retracting the lips and showed a good interdigitation of the teeth. Several teeth presented gingival recession, but it was not worsening compared to pretreatment. The posttreatment panoramic radiograph revealed acceptable root parallelism with no significant root resorption (Fig 3). The 3.4 month retention records showed good retention without any obvious relapse (Fig 4).

As shown on the pretreatment and posttreatment cephalometric superimposition (Fig 5), the maxillary and mandibular anterior teeth were retracted with the intrusion, the right maxillary posterior teeth were distalized, the left maxillary posterior teeth were intruded, the right mandibular posterior teeth were protracted and slightly uprighted and intruded, and the left mandibular posterior teeth were slightly protracted, uprighted and extruded. The FMA was slightly decreased. The Z-angle was improved from $65.6^{\circ}$ to $74.5^{\circ}$ (Table 1 ). All these changes helped improve the facial profile (Fig 6). The post-treatment and 34-month retention cephalometric superimposition (Fig 7) showed denture recovery such as slight extrusion and labial movement of upper anterior teeth, and slight extrusion of the posterior teeth.
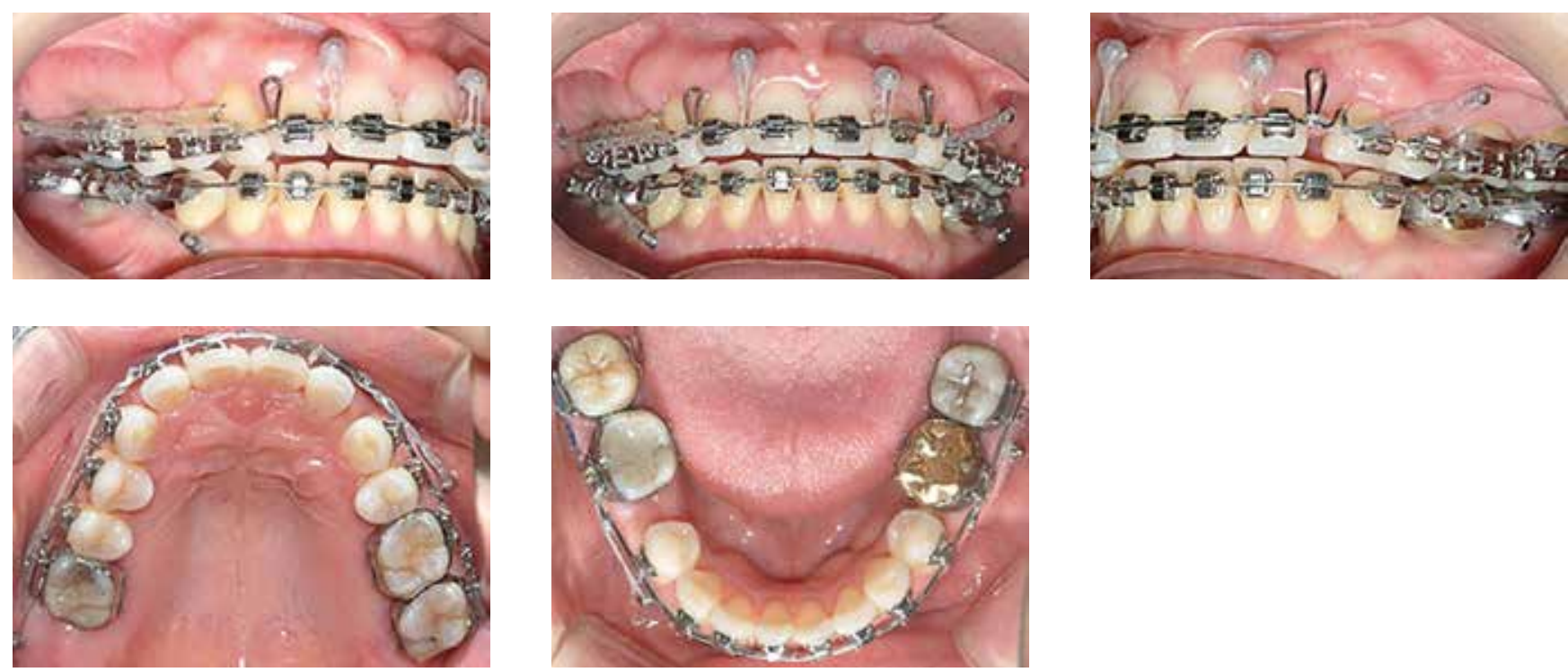

Figure 6 - Progress of treatment. Mini-implants to mesial movement of right mandibular molars and Clip on maxillary anterior mini-implants to prevent soft tissue irritation. 

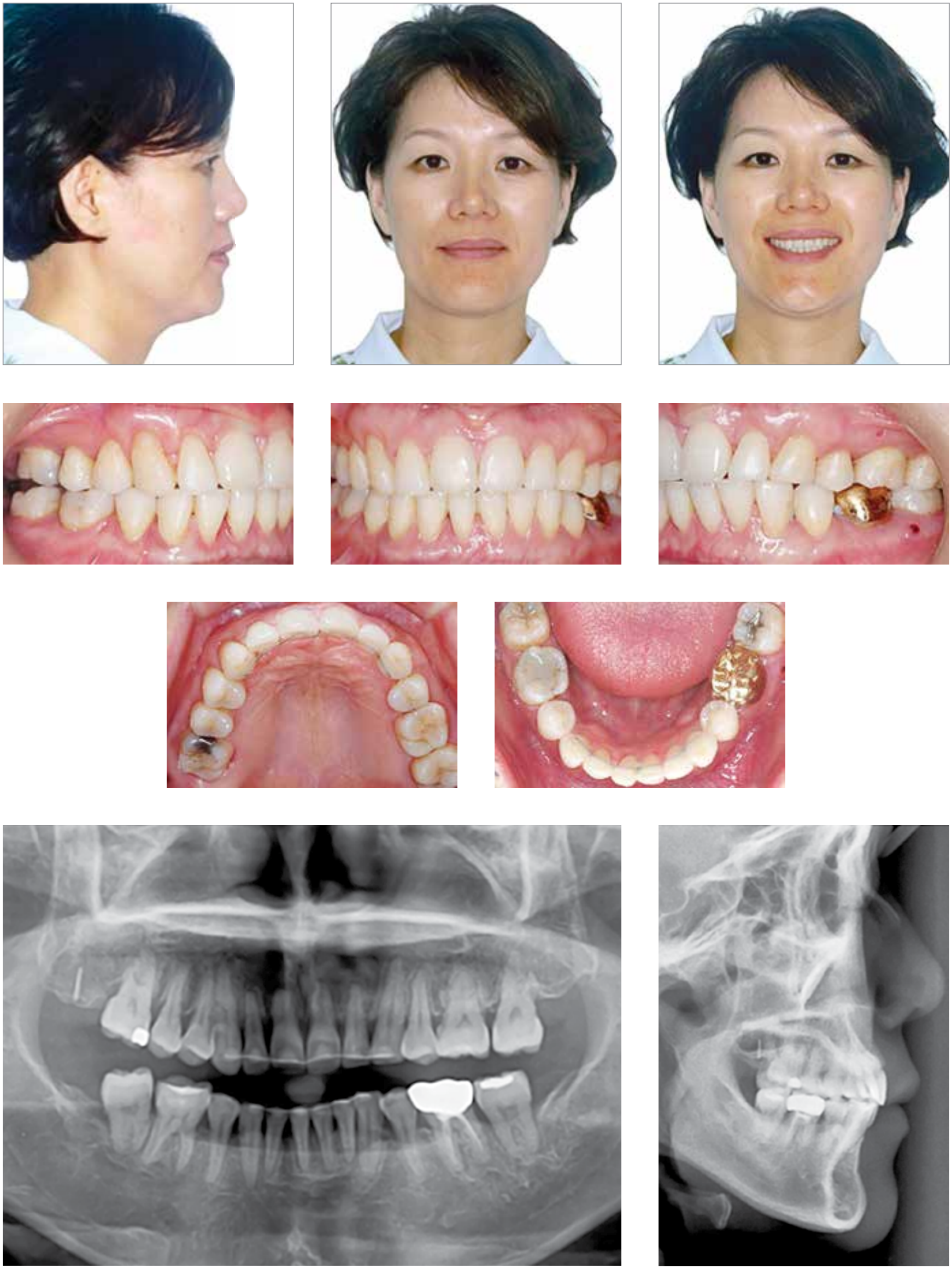

Figure 7 - Photographs and radiographs after treatment. 

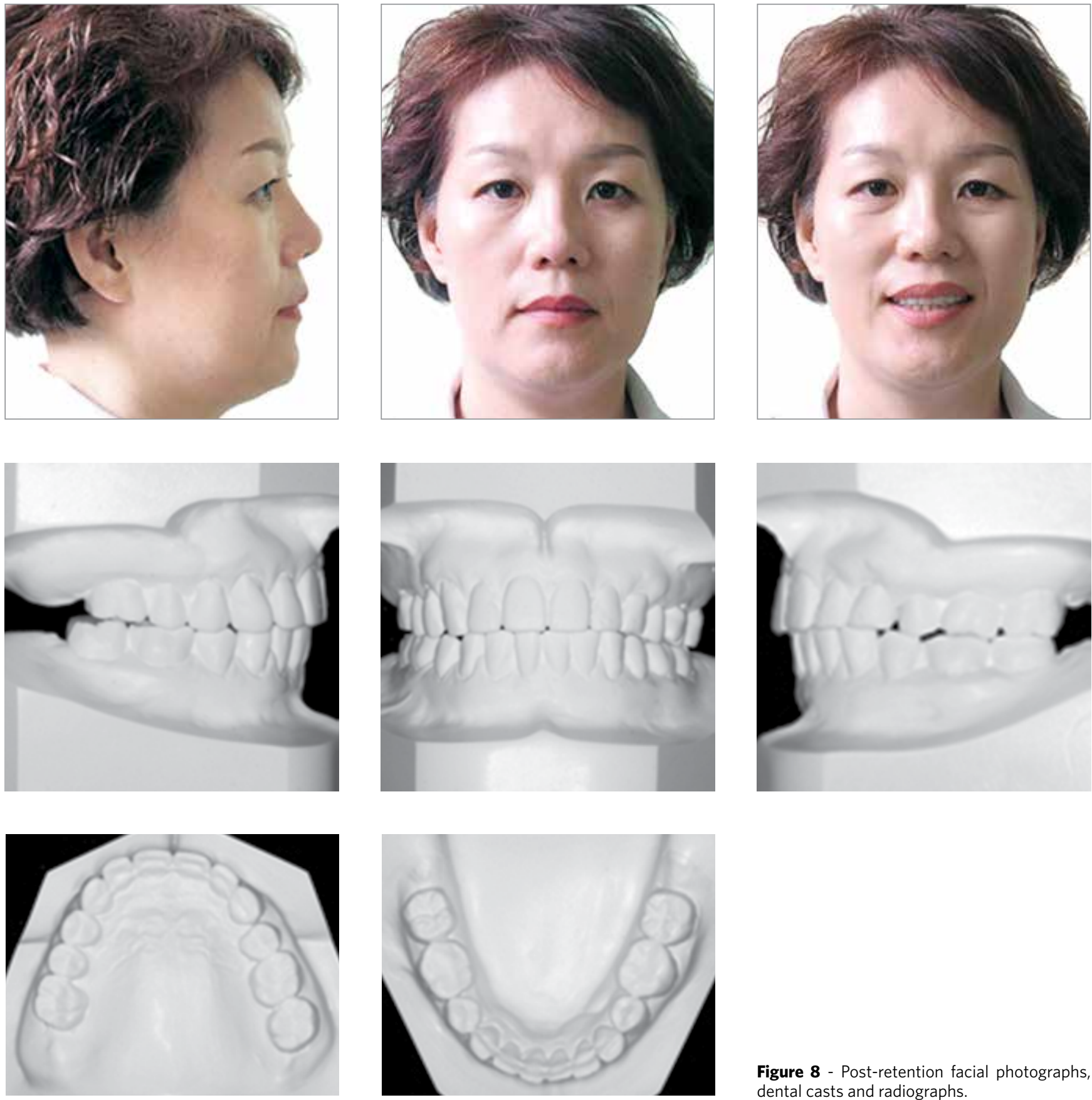

Figure 8 - Post-retention facial photographs, dental casts and radiographs.
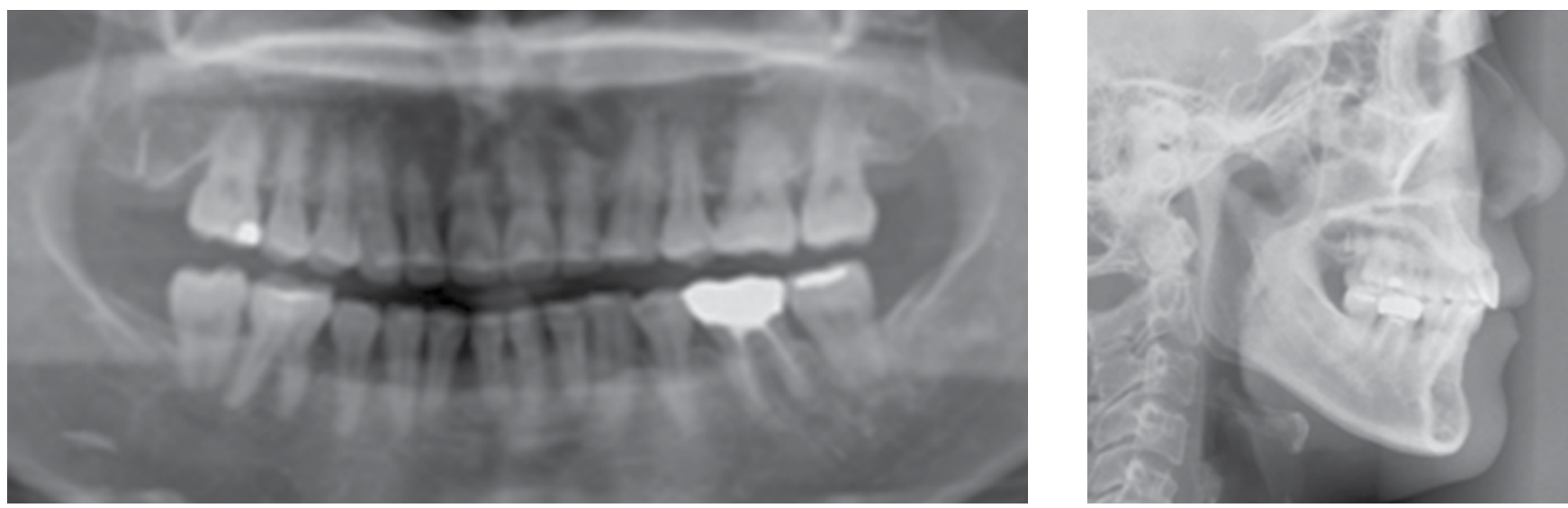

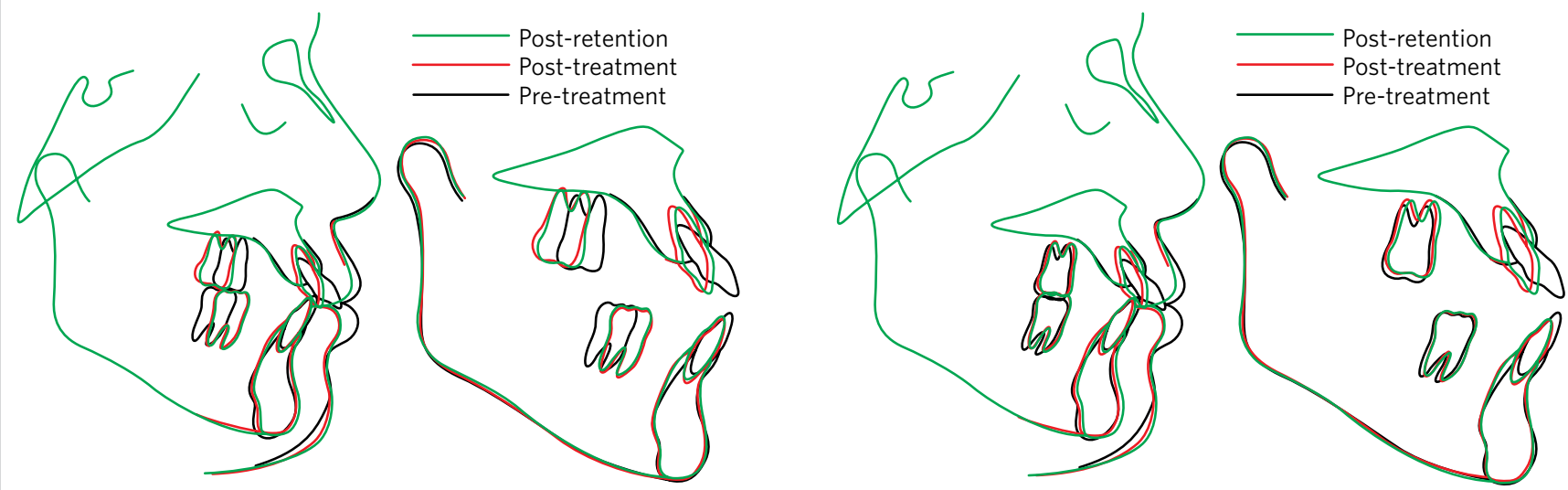

A

B

Figure 9 - Cephalometric overlays. A) Right side; B) Left side.
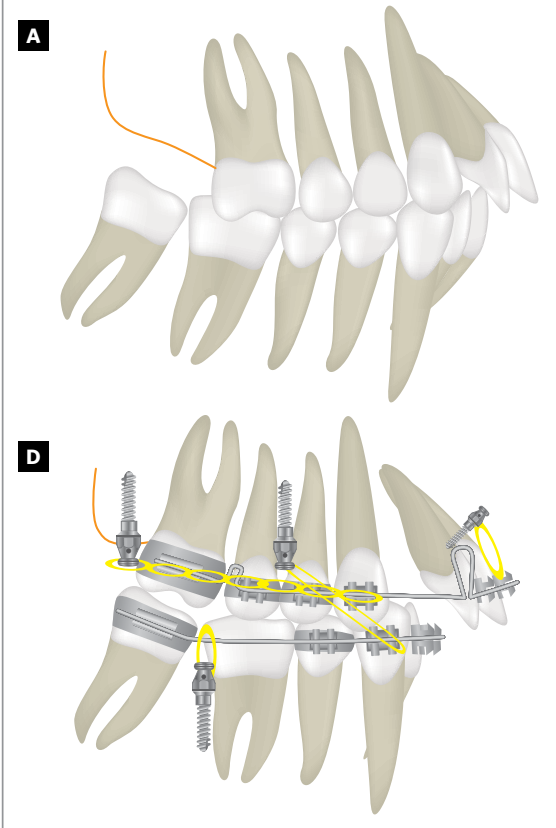

G

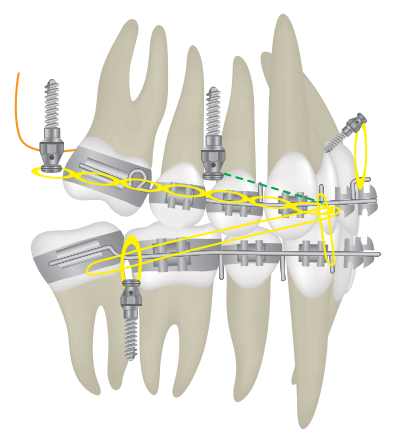

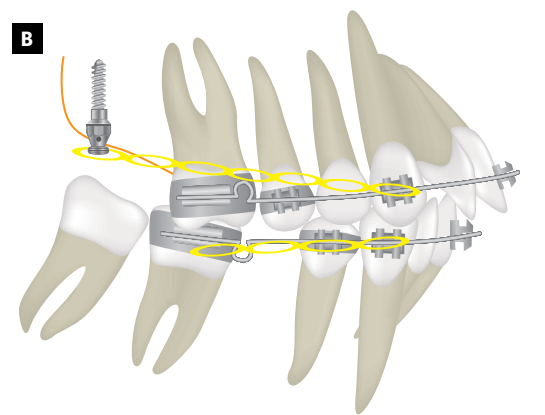

E

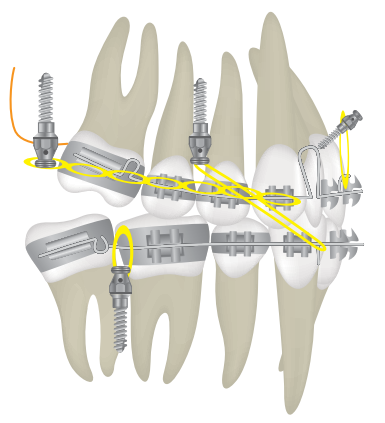

H

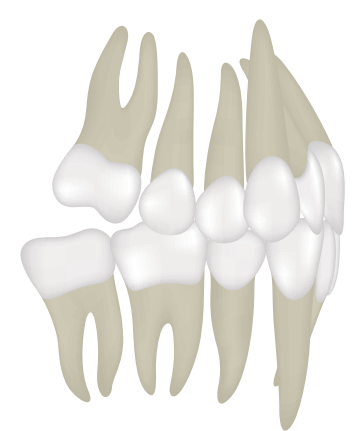

c

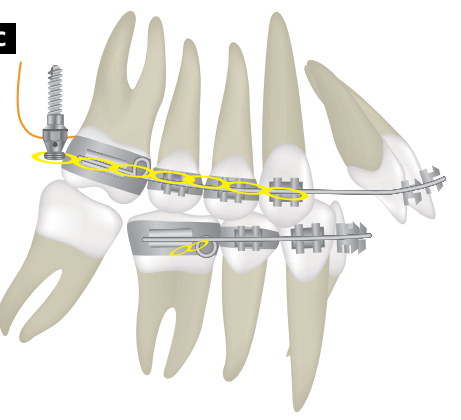

E

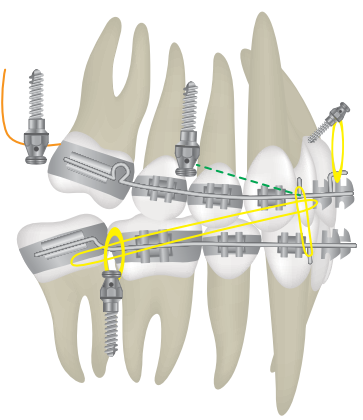

1

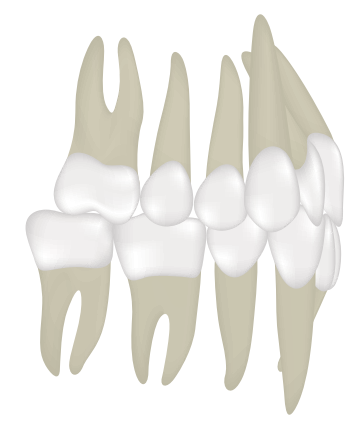

Figure 10 - Schematic diagram of the use of mini-implant anchorage (MIA) in the case of an unusual extraction in the treatment of Class II bialveolar protrusion: A) Before treatment; B) placement of mini-implant in the maxillary tuberosity area and the application of a distalizing force to the maxillary posterior teeth, running loop in the mandibular arch for leveling and en masse retraction; C) distalization of the maxillary posterior teeth and space closure in mandibular arch; D) placement of the maxillary anterior mini-implant and $0.020 \times 0.025$-in closing loop archwire for en masse retraction of maxillary four anterior teeth, mandibular anchorage preparation with mandibular mini-implants and Class III elastics; E) space closure in maxillary arch, continued mandibular anchorage preparation; $\mathbf{F}$ ) directional forces; $\mathbf{G}$ ) denture completion; $\mathbf{H}$ ) tweed occlusion; I) denture recovery. 


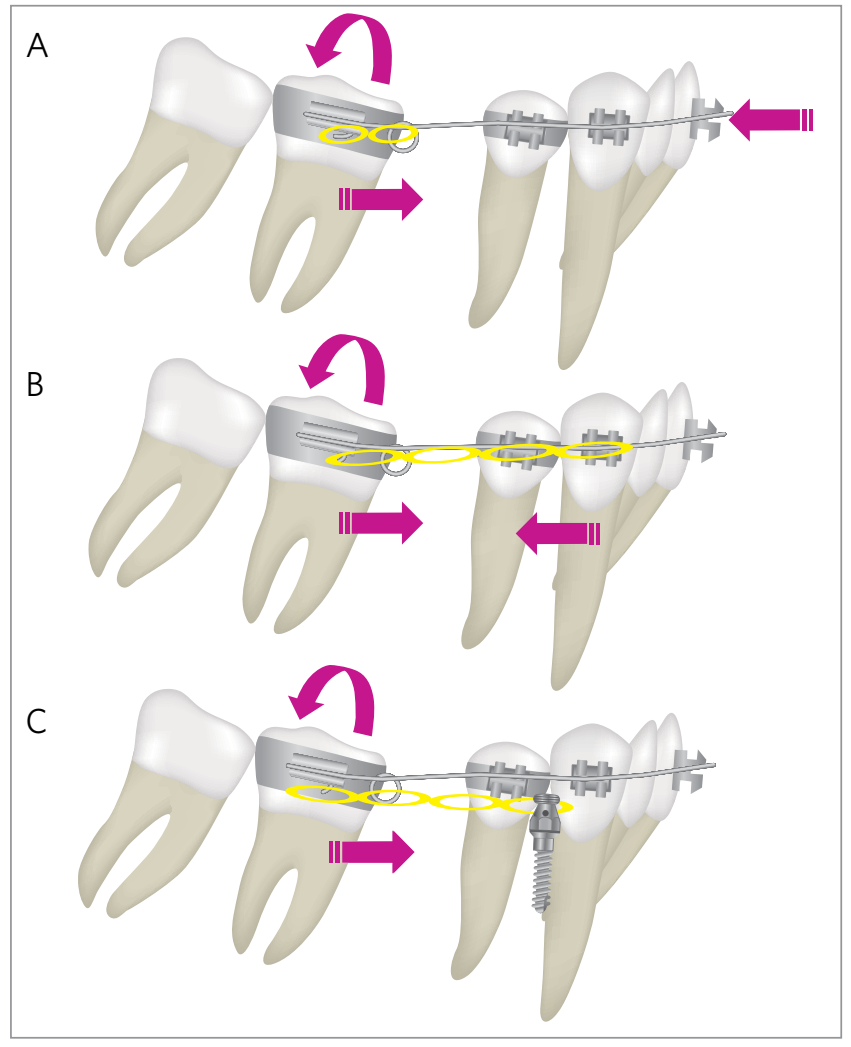

\section{DISCUSSION}

There are many clinical situations necessitating for unusual extraction of molars, including extensive caries, large restorations. A second molar extraction is indicated when (1) they are severely carious, ectopically erupted, or severely rotated, (2) mild-tomoderate arch length deficiencies exist with good facial profiles and (3) there is crowding in the posterior area with a need to facilitate first molar distal movement. ${ }^{13}$ The patient had a severely decayed maxillary second molar on the right side (1.7). Therefore, it was removed as an alternative to an extraction of the maxillary right first premolar (1.4).

When the second molars are extracted from patients with bialveolar protrusion, group distal movement of the remaining posterior teeth and a maximum retraction of the anterior teeth are essential for preserving healthy sound premolars and achieving the treatment goal. Numerous extraoral and intraoral appliances have been proposed for distalizing the posterior teeth. ${ }^{5}$ However, these appliances have disadvantages such as the need for patient cooperation, tipping movement, anchorage loss, and flaring of the incisors.
Figure 11 - Biomechanics of running loop archwire in lateral view. Uprighting and mesial movement of molars in the case of no crowding $(\mathbf{A})$ and crowding (B) in the anterior teeth, and using mini-implant anchorage (C).

The clinical efficacy ${ }^{12,14}$ and stability ${ }^{15}$ of temporary skeletal anchorage devices have been widely described. It is a very efficient method for solving orthodontic problems that cannot be corrected using conventional methods. Several skeletal anchorage devices that are efficient in controlling anchorage have been developed to obtain anchorage control during the distalization movement.

Using MI, distalization of the maxillary right posterior teeth into the second molar extraction space followed by a maximum en masse retraction of the maxillary anterior teeth are possible without patient compliance. During retraction of the anterior teeth, MIA was used to prevent the mesial movement of the posterior teeth and intrude the upper anterior teeth (Fig 8). ${ }^{12}$

The vertical and horizontal component of force is determined by the vertical position of MI head. The maxillary right posterior teeth appeared to have a tendency toward distal tipping with a slight intrusion, which was appropriate in this case. Therefore, the position of MI head should be considered carefully according to the type of malocclusion, and the 

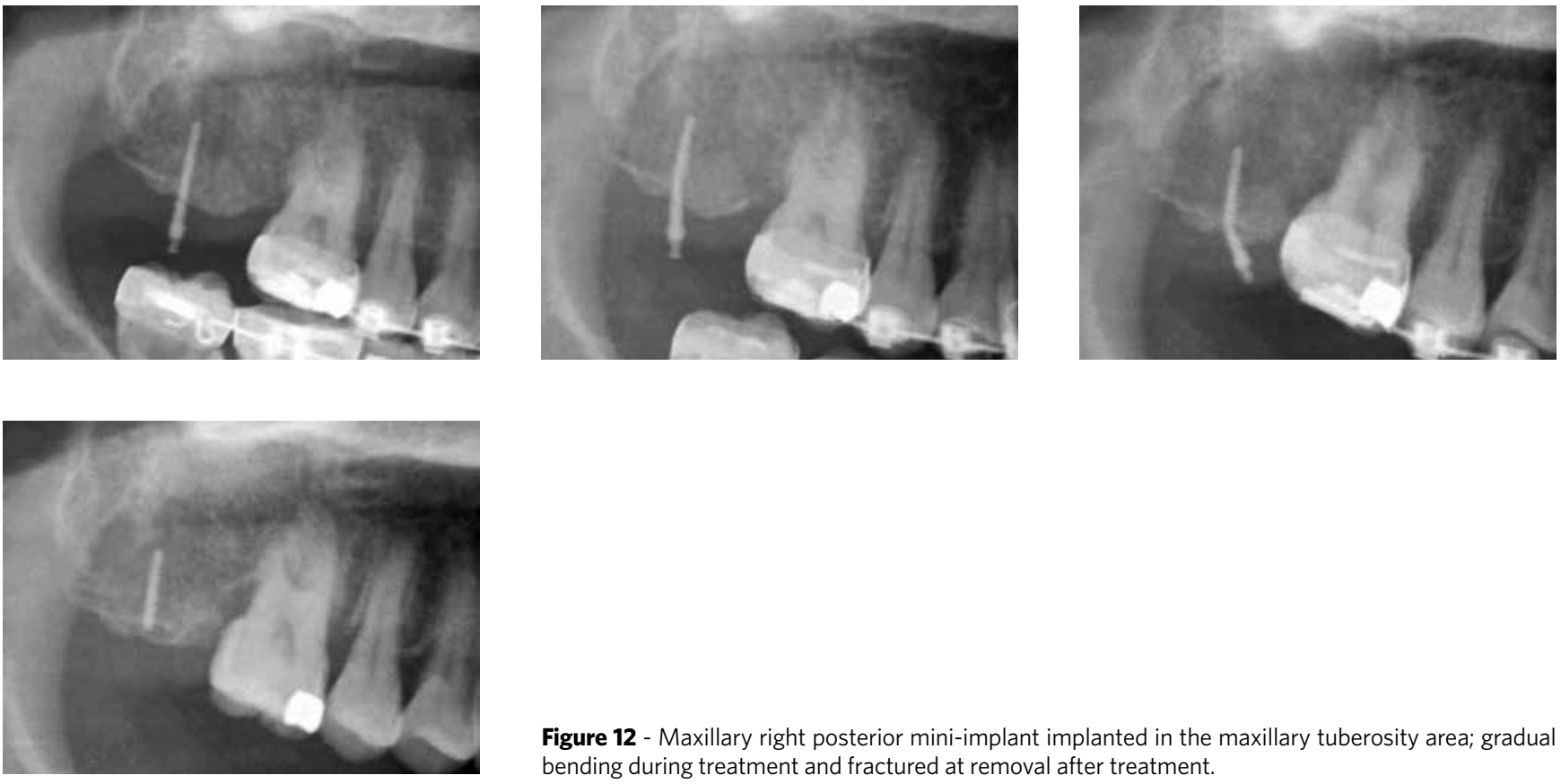

Figure 12 - Maxillary right posterior mini-implant implanted in the maxillary tuberosity area; gradual bending during treatment and fractured at removal after treatment.

amount and direction of tooth movement required. ${ }^{11}$ In this case, a MI with a small diameter and long length was chosen to increase the success rate in the maxillary tuberosity area which is generally not suitable for screw implantation due to its limited amount of cortical bone. . $^{16,17}$

Based on the patient's chief complaint and the diagnosis of the malocclusion, an extraction of mandibular second premolars is a viable option for decreasing lip procumbency. However, at the beginning of treatment, mandibular right second premolar was not extracted for a more predictable result. An elastic chain force was loaded from the mandibular right posterior MI to the mandibular right canine bracket to distalize the mandibular right posterior teeth for an alignment of the lower anterior teeth (Fig 2B). However, the patient wanted to correct lip protrusion more and the posterior limit of mandibular arch did not allow for more distalization of the posterior teeth to satisfy the patient's esthetic desire. Therefore, the mandibular right second premolar (4.5) was removed in the middle of treatment resulting in a long treatment time.

Running loops were used in the lower arch to retract the anterior teeth and protract posterior teeth (Fig 2D). The advantages of running loops for space closure are simple wire bending, fewer changes of archwires, and shorter treatment times due to the simultaneous uprighting and mesial movement of the molars. The desired amount and direction of tooth movement can be obtained by the simple and various applications of elastic chains and MIs (Fig 7). ${ }^{18}$ In this case, the MI was used to close the remaining space after retracting and protracting the lower anterior and posterior teeth respectively.

Clip or Fermit (Ivoclar Vivadent, clear, light-cured adhesive used for temporary restorations of inlay preparations ) is useful for relieving the soft-tissue irritation from an orthodontic appliance. In this case, it was used to prevent irritation from upper anterior MIs (Fig 2E). It has many advantages comparing with conventional OrthoWax - e.g., ease of placement and removal, possible placement in most areas of the orthodontic appliance and long retention time. ${ }^{19}$

All MIs remained firm throughout the treatment. After treatment, they were removed by unscrewing without anesthesia. However, maxillary right posterior MI implanted in the maxillary tuberosity area had bent gradually during treatment and fractured during removal after treatment. The fractured MI was left in its position with the consent of the patient (Fig 8). Further examinations will be necessary to prevent any pathologic conditions. The screw fragment embedded 
in the cortical bone can be surgically removed. A fullthickness flap is made, bone is cleared from around the fractured screw, and reverse torque is applied to the screw to remove the fragment. If the fragment encroaches on vital structures, however, it should be left in the bone, considering that orthodontic implants are made of biocompatible titanium. ${ }^{20}$

\section{REFERENCES}

1. Bills DA, Handelman CS, BeGole EA. Bimaxillary dentoalveolar protrusion: traits and orthodontic correction. Angle Orthod. 2005 May;75(3):333-9.

2. Janson G, Brambilla AC, Henriques JFC, Freitas MR, Neves LS. Class II treatment success rate in 2- and 4-premolar extraction protocols. Am J Orthod Dentofacial Orthop. 2004 Apr;125(4):472-9.

3. Janson G, Maria FRT, Barros SEC, Freitas MR, Henriques JFC. Orthodontic treatment time in 2- and 4-premolar-extraction protocols. Am J Orthod Dentofacial Orthop. 2006 May;129(5):666-71.

4. Janson G, Janson M, Nakamura A, de Freitas MR, Henriques JF, Pinzan A. Influence of cephalometric characteristics on the occlusal success rate of Class II malocclusions treated with 2- and 4-premolar extraction protocols. Am J Orthod Dentofacial Orthop. 2008 Jun;133(6):861-8.

5. Bondemark L, Karlsson I. Extraoral vs intraoral appliance for distal movement of maxillary first molars: a randomized controlled trial. Angle Orthod. 2005 Sep;75(5):699-706.

6. Onca G, Akyalçin S, Arikan F. The effectiveness of a single osseointegrated implant combined with pendulum springs for molar distalization. Am J Orthod Dentofacial Orthop. 2007 Feb;131(2):277-84.

7. Sugawara J, Kanzaki R, Takahashi I, Nagasaka H, Nanda R. Distal movement of maxillary molars in nongrowing patients with the skeletal anchorage system. Am J Orthod Dentofacial Orthop. 2006 Jun;129(6):723-33.

8. Gelgör IE, Büyükyilmaz T, Karaman Al, Dolanmaz D, Kalayci A. Intraosseous screwsupported upper molar distalization. Angle Orthod. 2004 Dec;74(6):838-50.

9. Escobar SA, Tellez PA, Moncada CA, Villegas CA, Latorre CM, Oberti G. Distalization of maxillary molars with the bone-supported pendulum: a clinical study. Am J Orthod Dentofacial Orthop. 2007 Apr;131(4):545-9.

\section{CONCLUSIONS}

Mini-implants can simplify the treatment plan and provide absolute anchorage for the distal movement of buccal teeth in a group as well as maximum retraction of the anterior teeth in an unusual maxillary second molar extraction treatment of dental Class II bialveolar protrusion.
10. Park HS, Lee SK, Kwon OW. Group distal movement of teeth using microscrew implant anchorage. Angle Orthod. 2005 Jul;75(4):510-7.

11. Chae JM. Unusual extraction treatment of Class I bialveolar protrusion using microimplant anchorage. Angle Orthod. 2007 Mar;77(2):367-76.

12. Chae JM. A new protocol of Tweed-Merrifield directional force technology with microimplant anchorage. Am J Orthod Dentofacial Orthop. 2006 Jul;130(1):100-9.

13. Bishara SE, Ortho D, Burkey PS. Second molar extractions: a review. Am J Orthod. 1986 May;89(5):415-24

14. Park HS, Bae SM, Kyung HM, Sung JH. Micro-implant anchorage for treatment of skeletal Class I bialveolar protrusion. J Clin Orthod. 2001 Jul;35(7):417-22.

15. Miyawaki S, Koyama I, Inoue M, Mishima K, Sugahara T, Takano-Yamamoto T. Factors associated with the stability of titanium screws placed in the posterior region for orthodontic anchorage. Am J Orthod Dentofacial Orthop. 2003 Oct;124(4):373-8.

16. Kuroda S, Sugawara Y, Deguchi T, Kyung HM, Takano-Yamamoto T. Clinical use of miniscrew implants as orthodontic anchorage: success rates and postoperative discomfort. Am J Orthod Dentofacial Orthop. 2007 Jan;131(1):9-15.

17. Poggio PM, Incorvati C, Velo S, Carano A. "Safe zones": a guide for miniscrew positioning in the maxillary and mandibular arch. Angle Orthod. 2006 Mar;76(20):191-7

18. Chae J, Kim S. Running loop in unusual molar extraction treatment. Am J Orthod Dentofacial Orthop 2007 Oct;132(4):528-39.

19. Kim TK, Park SH. Relief of soft-tissue irritation from orthodontic appliances. J Clin Orthod. 2002 Sep;36(9):509.

20. Jolly $\mathrm{TH}$, Chung $\mathrm{CH}$. Peak torque values at fracture of orthodontic miniscrews. J Clin Orthod 2007 Jun;41(6):326-8. 